Review Article

\title{
Diagnosis and Treatment of Tuberculosis using Nanotechnology
}

P Deeksha*, S Antinate Shilpa**, GS Hikku***

*Undergraduate Student, *Research Scholar, *Assistant Professor, Medical Bionanotechnology, Faculty of Allied Health Sciences, Chettinad Hospital and Research Institute, Chettinad Academy of Research and Education, Kelambakkam, Tamilnadu, India.

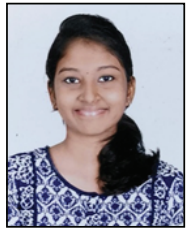

Ms. P Deeksha is a B.Sc. III-year student, Department of Medical Bionanotechnology, Faculty of Allied Health Sciences, Chettinad Academy of Research and Education, Kelambakkam - 603103, Tamilnadu. Her area of interest is targeted drug delivery.

Corresponding author - Dr. G.S. Hikku - (gshikku@gmail.com)

Chettinad Health City Medical Journal 2020; 9(1): 49 - 52

DOI: https://doi.org/10.36503/chcmj9(1)-09

\begin{abstract}
Tuberculosis (TB) is a chronic disease which is one of the reasons behind millions of deaths all over the world. This infectious disease is contagious and can be transmitted via sputum, aerosol droplets, thus it is an air-borne disease. TB can be treated using certain drugs to inhibit the bacterial growth, but the main drawback is that they provide less bioavailability and show toxicity to normal cells. Another challenging part is the diagnosis of TB at its early stage though many techniques and equipment's are developed. In this context, the present short review describes how nanotechnology can be utilized as a diagnostic and therapeutic tool to detect TB at developmental stage and treat it through targeted drug delivery.
\end{abstract}

Key words : Tuberculosis; nanotechnology; diagnostic tool; targeted drug delivery.

\section{Overview}

Tuberculosis (TB) is an air-borne disease which is caused majorly by Mycobacterium tuberculosis and Mycobacterium bovis. ${ }^{1}$ It does not infect only the lungs but if left untreated it reaches the bloodstream and affect other parts of the body such as spine, kidney, liver, brain, etc. where such type of infection is called as military TB. Patients with active TB shows symptoms like chronic cough, mucus-containing blood, fever, night sweats, loss of appetite, fatigue, etc.Patients with latent TB show no symptoms and fail to spread infection from one person to another person so they are said to be non-contagious. ${ }^{2}$ Active TB mostly occurs in patients with low immunity, or patients with primary infections like HIV/AIDS, people who smoke and also in young children. Active patients can spread infection via cough and sneeze where a single sneeze approximately releases about 40,000 droplets containing disease causing agents, so they are found to be contagious. Transmission depends on some factors such as number of infectious droplets expelled by the carrier, effectiveness of the ventilation, duration of the exposure, virulence of bacterial strain, level of immunity in the uninfected person, etc. There are many types of TB infections depending on the area at which it is affected such as pulmonary TB, extrapulmonary TB, TB lymphadenitis, skeletal TB, military TB, genitourinary TB, liver TB, gastrointestinal TB, TB meningitis, TB peritonitis, TB pericarditis, cutaneous
TB and so on. ${ }^{2}$ TB infection begins when Mycobacteria enters the alveolar air sacs of the lungs and starts to replicate within the endosomes of alveolar macrophages. Macrophages identify the foreign bacteria and try to eliminate it by phagocytosis. In this process, the bacteria are enfolded by macrophage and remain in the membrane bound vesicle called phagosome. Phagosome combines with lysosome to form phagolysosome. Phagolysosome use reactive oxygen species and acid to kill the bacteria. However, the bacteria with thick lipid and mycolic acid present in the cell membrane protect them from immunity response enabled by phagolysosome. Therefore, the bacteria present in the phagolysosome are able to replicate without any trouble and weakens the immune system.

\section{Development of diagnostic tool using nanotechnology}

Some of the current diagnostic tools used for the detection of tuberculosis are acid fast bacilli (AFB), loop mediated isothermal amplification diagnosis of pulmonary TB, gene Xpert MTB/RIF assay, lipoarabinomannan urine test for TB diagnosis in HIV infected patients, culture for TB diagnosis, molecular line probe assays diagnosis of TB, TB skin test for diagnosis of latent TB infection, etc. ${ }^{3}$ These diagnostic techniques show low sensitivity towards bacterial infection and may provide false conclusion. The major problem 
in the treatment of tuberculosis is the diagnosis at its early stage. ${ }^{3}$ Using nanotechnology-based sensing devices, the detection of Mycobacterium tuberculosis at early stage can be performed. 4 In the field of nanomedicine, nanoparticles (Nps) are considered to be effective carriers. Solid lipid Nps, polymeric Nps, dendrimers, nano emulsions, nanosuspensions and other nano systems which have provided unique properties to improve the sensitivity in diagnosis. 4 Some of the Nps based diagnostic tools are discussed here. Quantum dots (QD) are semiconductor nanocrystals with the size ranging between $2 \mathrm{~nm}$ to $10 \mathrm{~nm} .5$ Depending upon on the size of the particle, it illuminates different colors which are used to identify Mycobacterium tuberculosis.5 The traditional methods like AFB and microscopic techniques detect specific antigen Ag85B for diagnosis TB infections. To diagnose the presence of $T B$, samples are visualized by conjugating antibodies with organic or inorganic dyes and observe them under fluorescent or electron microscope. However, this method has limited specificity and low sensitivity. ${ }^{3}$ To give a complete diagnosis without any false confirmation, quantum dots are used. Kim et al. ${ }^{6}$ developed a sandwich-based assay to detect TB by antigen-antibody interaction using silica coated QDs. Genetically engineered antibody GBP-50B14 and $\mathrm{SiBP}-8 \mathrm{~B} 3$ are used to functionalize the surface of QDs. The targeted antigen Ag85B bind to the specific antibody and interaction takes place between them which shows quenching effect. Quenching refers to the decrease in fluorescence effect of QDs owing to the interaction of antigens to antibodies which are attached over its surface. The detection limit is found to be $13.0 \mathrm{pg} \mathrm{mL}^{-1}$.
Silicon Nps having fluorescence property along with the help of immunofluorescence microscopy provides high sensitivity detection of Mycobacterium tuberculosis. Qin et al.7 utilized two-color flow cytometric technique by combining fluorescent silica Nps and SYBR green I for the detection of Mycobacterium tuberculosis. Anti-Mycobacterium tuberculosis is immobilized over Nps by (2,2 bipyridyl) dichlororuthenium(II) hexahydrate,treated with the sample containing Mycobacterium tuberculosis, stained with SYBR dye which acts as nucleic acid stain to remove the influence of unwanted waste particles. The presence of Mycobacterium tuberculosis is detected using mutiparameter determination with flow cytometry. This method provides high sensitivity with detection limit as low as $3 \times 10^{4}$ cells $\mathrm{ml}^{-1}$ in spiked urine. Likewise, there are many nanosystems which can enhance the sensing ability of diagnosis systems which are summarized in Table 1.

\section{Targeted drug delivery through nano- technology}

Even though, the disease is diagnosed, conventional medications used to treat TB involve long-term medication, high dosage, low bioavailability, low bio-absorption, poor drug solubility and nontargeted drug delivery which also affects the healthy cells and causes side effects. To treat TB, anti-infectious drugs are administrated, but reach the circulatory system and damages healthy cells. To overcome this drawback, researchers have been utilizing nanoparticles (Nps) for targeted drug delivery. Nps that are engineered using polymers, proteins, lipid, etc. are widely used as drug delivery carrier system which is usually conjugated with imaging and therapeutic compounds for simultaneous diagnosis and therapeutic effect. 4

\begin{tabular}{|c|c|c|}
\hline SI. No. & Nanosystems & Description \\
\hline 1. & $\begin{array}{l}\text { Dual labeled Au Nps as } \\
\text { electrochemical biosensor }\end{array}$ & $\begin{array}{l}\text { Enzyme probe and detection probes are used. } \\
\text { Detection limit is } 1.25 \mathrm{ng} / \mathrm{ml} \text { genomic DNA. }{ }^{8}\end{array}$ \\
\hline 2. & $\begin{array}{l}\text { Magnetic nanoparticles with } \\
\text { chemiluminescence }\end{array}$ & $\begin{array}{l}\text { Magnetic nanoparticles capture target DNA and intensifies } \\
\text { chemiluminescence signal. }{ }^{9}\end{array}$ \\
\hline 3. & $\begin{array}{l}\text { Surface plasmon resonance } \\
\text { sensing chip with graphene - } \\
\text { ssDNA-gold nano urchin }\end{array}$ & $\begin{array}{l}\text { Graphene lay ers placed on the surface of the chip. ssDNA -gold } \\
\text { nano urchin binds to the graphene by stacking force. In the } \\
\text { presence of cssDNA from Mycobacterium tuberculosis } \\
\text { disrupts the ssDNA which is bounded to gold nano -urchin } \\
\text { resulting the change in SPR. }{ }^{10}\end{array}$ \\
\hline 4. & Au Nps & Direct detection of MTB 16s rDNA"! \\
\hline 5. & $\begin{array}{l}\text { Graphene modified iron -oxide } \\
\text { chitosan nano -composite film } \\
\text { coated over fluorine tin oxide }\end{array}$ & $\begin{array}{l}\text { Using streptavidin biotin interaction, DNA aptamer sequence } \\
\text { specific to the MPT64 antigen is immobilized onto composite } \\
\text { film which acts as a voltammetric biosensor having low } \\
\text { detection of limit } 0.9 \text { fg.mL } \mathrm{mL}^{-1} .^{12}\end{array}$ \\
\hline
\end{tabular}




\begin{tabular}{|c|c|c|c|}
\hline $\begin{array}{l}\text { Sl. } \\
\text { No. }\end{array}$ & $\begin{array}{l}\text { Nanoparticles in drug } \\
\text { delivery }\end{array}$ & Drugs & Virulent organisms \\
\hline 1. & Alginate Nps ${ }^{17}$ & $\begin{array}{l}\text { Isoniazid, rifampicin and } \\
\text { pyrazinamide }\end{array}$ & Mycobacterium tuberculosis \\
\hline 2. & Solid lipid Nps ${ }^{18}$ & $\begin{array}{l}\text { Isoniazid, rifampicin and } \\
\text { pyrazinamide }\end{array}$ & Mycobacterium tuberculosis \\
\hline 3. & Liposomal aerosols ${ }^{19}$ & Rifampicin & Mycobacterium smegmatis \\
\hline 4. & Liposomal Nps 20 & Rifampin & Mycobacterium tuberculosis \\
\hline 5. & $\begin{array}{l}\text { Poly (lactic -co-glycolic } \\
\text { acid) }\end{array}$ & Isoniazid, rifampin, pyrazinamide & Mycobacterium tuberculosis \\
\hline 6. & $\begin{array}{l}\text { Nano-suspension of ( } 385 \\
\mathrm{~nm} \text { ) clofazimine } 22\end{array}$ & Clofazimine & Mycobacterium avium \\
\hline
\end{tabular}

Using Nps as drug carriers have many advantages such as good bioavailability, required dosage which ultimately reduce the side effects, preventing the damage caused to healthy cells. Liposomal Nps loaded with drug has the ability to bind with microorganism's cellular membrane, penetrate into microorganism's surface and deliver drugs into the organism. ${ }^{13}$ Therefore, drug loaded liposomal Nps can be used to kill the pathogenic organisms which causes disease. For selectively, Nps are targeted towards surface receptors of the microorganisms by functionalizing Nps surface with complementary antibodies which further improves the therapeutic efficiency.

Rifampicin is one of the most effective anti-TB drugs used as oral administration. Grotz et al. ${ }^{14}$ used polymeric micelles made up of co-polymer of poly (vinyl caprolactam), poly(vinyl-acetate) and poly(ethylene glycol) as nanocarrier to encapsulate rifampicin. The size of the nanocarrier ranges about $107 \mathrm{~nm}$. This type of nanocarrier can able to penetrate deep into the lungs to deliver drug at the target site through inhalation. Similarly, Bashaet al. ${ }^{15}$ loaded rifampicin and levofloxacin drugs in cyclodextrin and conjugated with curdlan Nps for controlled and sustain release of both the drugs for a long period which does not destroy normal cells. The main advantage of this system is that they are non-cytotoxic to both RAW264.7 and L929 cell lines. Another route of drug delivery is the use of magnetic chitosan Nps as drug carrier. ${ }^{16}$ The drug chosen is isoniazid which is considered to be the first line of anti-tuberculosis drug that are incorporated into the magnetic chitosan Nps through ionic gelation method. The prepared system provides a gradual sustained release of drug in the targeted site avoiding contact with the normal cells, provides good biocompatibility and display non-toxicity. There are many literatures that dealt with the targeted drug delivery for TB infection some of which are summarized in Table 2.

\section{Conclusion}

From the discussions provided in this review, it is clear that nanomedicine can diagnosis and treat tuberculosis with safety, efficacy, biocompatibility, less toxicity, prevent drug degradation and enable sustained drug release at targeted site. So, it can be concluded that even though there are many deadly diseases that persist within human community, with the advancement of nanotechnology in medicine, it is possible to diagnosis the disease at its early stage and treat it with at most care without damaging the normal cells.

\section{Acknowledgments}

The authors would like to thank the Management of Chettinad Academy of Research and Education, Kelambakkam for providing facilities to complete this work.

\section{References}

1. Torres-Gonzalez P, Cervera-Hernandez ME, Martinez-Gamboa A, Garcia-Garcia L, Cruz-Hervert LP, Bobadilla-del Valle M, Ponce-de Leon A, Sifuentes-Osornio J. Human tuberculosis caused by Mycobacterium bovis: a retrospective comparison with Mycobacterium tuberculosis in a Mexican tertiary care centre, 2000-2015. BMC infectious diseases. 2016;16:657.

2. American Thoracic Society. Targeted tuberculin testing and treatment of latent tuberculosis infection. Am J RespirCrit Care Med. 2000;161:S221-47.

3. Matsui H. Exciton-Plasmon Interactions in Quantum Well Structures Near Silver Nanoparticles. In: Noble and Precious Metals-Properties. Nanoscale Effects and Applications.IntechOpen; 2017. 
4. Banyal S, Malik P, Tuli HS, Mukherjee TK. Advances in nanotechnology for diagnosis and treatment of tuberculosis. Current opinion in pulmonary medicine. 2013;19:289-97.

5. Cheepsattayakorn A, Cheepsattayakorn R. Roles of nanotechnology in diagnosis and treatment of tuberculosis. Journal of Nanotechnology in Diagnosis and Treatment. 2013; 1: 19-25.

6. Kim EJ, Kim EB, Lee SW, Cheon SA, Kim HJ, Lee J, Lee MK, Ko S, Park TJ. An easy and sensitive sandwich assay for detection of Mycobacterium tuberculosis Ag85B antigen using quantum dots and gold nanorods. Biosensors and Bioelectronics. 2017; 87:150-6.

7. Qin D, He X, Wang K, Tan W. Using fluorescent nanoparticles and SYBR Green I based two-color flow cytometry to determine Mycobacterium tuberculosis avoiding false positives. Biosensors and Bioelectronics. 2008; 24:626-31.

8. Thiruppathiraja C, Kamatchiammal S, Adaikkappan P, Santhosh DJ, Alagar M. Specific detection of Mycobacterium sp. genomic DNA using dual labeled gold nanoparticle based electrochemical biosensor. Analytical biochemistry. 2011; 417:73-9.

9. Chen Q, Li Z, Liu B, He B, Wei X, Du J, Fan L. Highly sensitive detection of mycobacterium tuberculosis for the diagnosis of osteoarticular tuberculosis based on magnetic nanoparticles and chemiluminescence. Journal of Biomaterials and Tissue Engineering. 2015; 5:241-5.

10. Pezzotta G, Pinto R, Pirola F, Ouretani MZ. Balancing product-service provider's performance and customer's value: the service engineering methodology (SEEM). In: 6th CIRP Conference on Industrial Product-Service Systems. Elsevier; 2014. pp.50-55.

11. Hussain MM, Samir TM, Azzazy HM. Unmodified gold nanoparticles for direct and rapid detection of Mycobacterium tuberculosis complex. Clinical biochemistry. 2013; 46: 633-7.

12. Thakur H, Kaur N, Sabherwal P, Sareen D, Prabhakar N. Aptamer based voltammetric biosensor for the detection of Mycobacterium tuberculosis antigen MPT64. MicrochimicaActa. 2017; 184:1915-22.

13. Gupta A, Mumtaz S, Li CH, Hussain I, Rotello VM. Combatting antibiotic-resistant bacteria using nanomaterials. Chemical Society Reviews. 2019;48:415-27.
14. Grotz E, Tateosian NL, Salgueiro J, Bernabeu E, Gonzalez L, Manca ML, Amiano N, Valenti D, Manconi M, García V, Moretton MA. Pulmonary delivery of rifampicin-loaded soluplus micelles against Mycobacterium tuberculosis. Journal of Drug Delivery Science and Technology. 2019; 53:101170.

15. Basha RY, TS SK, Doble M. Dual delivery of tuberculosis drugs via cyclodextrin conjugated curdlan nanoparticles to infected macrophages. Carbohydrate Polymers. 2019; 218:53-62.

16. Qin $\mathrm{H}$, Wang CM, Dong QQ, Zhang L, Zhang X, Ma ZY, Han QR. Preparation and characterization of magnetic $\mathrm{Fe}_{3} \mathrm{O}_{4}$-chitosan nanoparticles loaded with isoniazid. Journal of Magnetism and Magnetic Materials. 2015; 381:120-6.

17. Zahoor A, Sharma S, Khuller GK. Inhalable alginate nanoparticles as antitubercular drug carriers against experimental tuberculosis. International journal of antimicrobial agents. 2005;26:298-303.

18. Pandey R, Khuller GK. Solid lipid particle-based inhalable sustained drug delivery system against experimental tuberculosis. Tuberculosis. 2005; 85:227-34.

19. Vyas SP, Kannan ME, Jain S, Mishra V, Singh P. Design of liposomal aerosols for improved delivery of rifampicin to alveolar macrophages. International journal of pharmaceutics. 2004;269:37-49.

20. Zaru M, Sinico C, De Logu A, Caddeo C, Lai F, Manca ML, Fadda AM. Rifampicin-loaded liposomes for the passive targeting to alveolar macrophages: in vitro and in vivo evaluation. Journal of liposome research. 2009;19:68-76.

21. Varghese S, Anil A, Scaria S, Abraham E. Nanoparticulate Technology in the treatment of tuberculosis: A review. International Journal of Pharmaceutical Sciences and Research. 2018; 9: 4109-16.

22. Peters K, Leitzke S, Diederichs JE, Borner K, Hahn H, Müller RH, Ehlers S. Preparation of a clofaziminenanosuspension for intravenous use and evaluation of its therapeutic efficacy in murine Mycobacterium avium infection. Journal of Antimicrobial Chemotherapy. 2000; 45: 77-83. 